\title{
Prevalence of pulmonary tuberculosis in Karachi juvenile jail, Pakistan
}

S.A. Shah, ${ }^{1}$ S.A. Mujeeb, ${ }^{2}$ A. Mirza, ${ }^{3}$ K.G. Nabi ${ }^{4}$ and Q. Siddiqui ${ }^{5}$

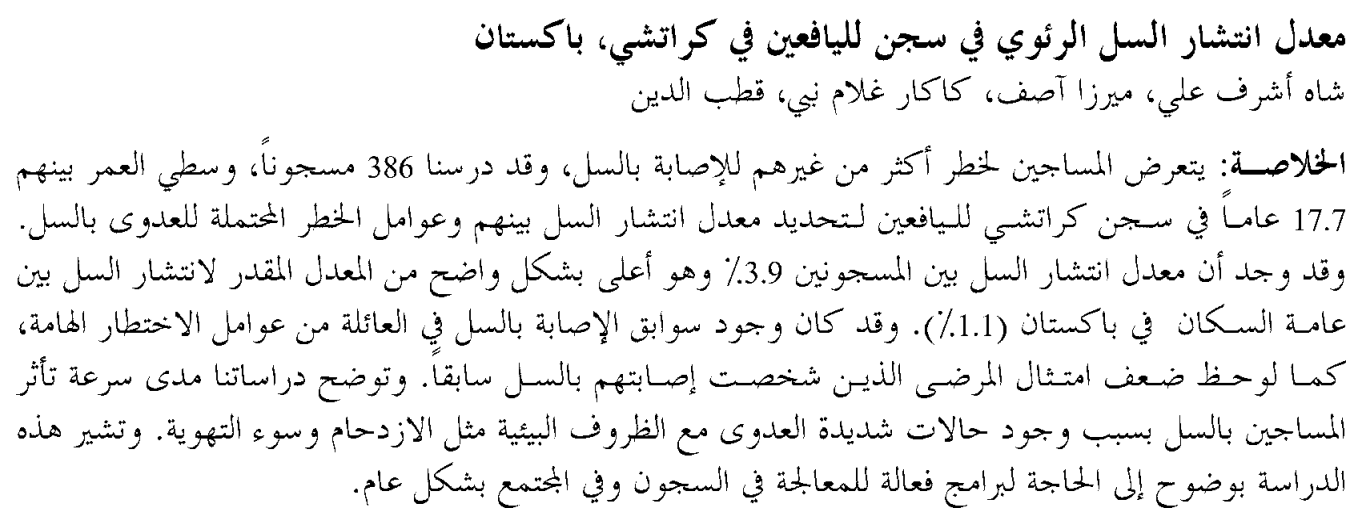

ABSTRACT Jail inmates may be at increased risk of contracting tuberculosis (TB). We studied 386 detainees (mean age 17.7 years) in Karachi juvenile jail to determine the prevalence of TB and possible risk factors for contracting TB. We found a 3.9\% prevalence of TB among the inmates, significantly higher than the estimated $1.1 \%$ prevalence in the general population of Pakistan. Positive family history of TB was a significant risk factor for TB. Poor adherence of previously diagnosed patients to anti-TB treatment was found. Our study highlights the vulnerability of inmates to TB owing to the presence of highly infectious cases, along with environmental conditions such as overcrowding and poor ventilation. This study strongly indicates the need for an effective treatment programme in the jails as well in the general community.

Prévalence de la tuberculose pulmonaire dans le centre de détention pour mineurs de Karachi (Pakistan)

RESUME Les détenus peuvent être exposés à un plus grand risque de contracter la tuberculose. Nous avons étudié 386 détenus (âge moyen 17,7 ans) dans le centre de détention pour mineurs de Karachi afin de déterminer la prévalence de la tuberculose et les facteurs de risque éventuels pour contracter la tuberculose. Nous avons trouvé que la prévalence de la tuberculose parmi les détenus était de 3,9\%, significativement plus élevée que la prévalence dans la population générale du Pakistan estimée à 1,1\%. Les antécédents familiaux positifs de tuberculose étaient un facteur de risque important pour la tuberculose. Nous avons constaté que les patients diagnostiqués antérieurement ne suivaient pas bien le traitement antituberculeux prescrit. Notre étude souligne la vulnérabilité des détenus face à la tuberculose en raison de la présence de cas très infectieux et des conditions environnementales comme la promiscuité et une mauvaise aération. Cette étude souligne fortement la nécessité d'un programme de traitement efficace dans les centres de détention ainsi que dans l'ensemble de la communauté.

${ }^{1}$ Sindh AIDS Control Programme, Karachi, Pakistan.

${ }^{2}$ Jinnah Postgraduate Medical Centre, Karachi, Pakistan.

${ }^{3}$ BRIDGE, Karachi, Pakistan.

${ }^{4}$ TB Control Programme, Karachi, Pakistan.

${ }^{5}$ Juvenile Jail, Karachi, Pakistan.

المجلة الصحية لشرق المتوسط، منظمة الصحة العالمية، المجلد التاسع، العدد ع، بr.. 


\section{Introduction}

Available data around the globe suggest that jail inmates are at increased risk of contracting pulmonary tuberculosis (TB) [1-3]. Factors such as overcrowding, malnutrition and limited access to health care services put prison inmates at high risk. Children and adolescents are even more vulnerable. There is increasing recognition that the high risk of TB in settings such as prisons, remand centres, police stations, detention centres for asylum seekers, penal colonies, and prisoner-of-war camps poses a problem for those imprisoned and for the wider society [2]. A study conducted in Mwanza, Tanzania, revealed that $40.7 \%$ of the prisoners studied had smear-positive TB [3].

Pakistan contributes $43 \%$ of the disease burden in the Eastern Mediterranean Region of the World Health Organization, and thus ranks sixth among the countries with the highest burden of disease for TB [4], but unfortunately there are limited data available regarding prevalence of TB among jail inmates in general, and juvenile detainees in particular. Through this study we proposed to determine the prevalence of pulmonary TB and the associated risk factors among juvenile detainees in Karachi in order to complement national and international efforts to control TB in the community in general and in prisoners in particular. The city of Karachi was selected for the study because it is the most populous city of the country, with a population of more than 10 million, and has residents from all parts of the country. The juvenile prison in Karachi reflects the same characteristics as the city, housing prisoners from all parts of the country and even from neighbouring countries.

The proposal for this study was approved by the Ethical Research Committee of Sindh AIDS control programme, Kara- chi, Pakistan. Study participants were recruited after obtaining informed written consent and all study participants diagnosed with TB were provided with free treatment through the government of Sindh directly observed treatment short course (DOTS) programme.

\section{Methods}

A cross-sectional study was conducted in the juvenile prison in Karachi during the calendar year 2002. The medical officer of the prison and technicians were trained in laboratory techniques, clinical diagnosis and management of TB with the DOTS strategy at Ojha Institute of Chest Diseases, Karachi, for 2 weeks. The technician and the prison dispenser also received training in sputum microscopy at the Institute of Chest Diseases.

All participants were interviewed using a structured questionnaire which included questions on sociodemographic characteristics, past and family history of TB, and other risk factors. They were then clinically examined by the medical officer.

Prisoners were suspected of having TB on the grounds of clinical findings, past history of diagnosis of TB infection and family history of the illness.

Individuals identified as suspected TB cases were investigated for acid-fast bacilli (AFB) in their sputum. A TB suspect was defined as any person who presented with symptoms or signs suggestive of TB, in particular cough of long duration (more than 2 weeks) [5].

Three specimens of sputum were then collected form the suspects and examined by microscopy using the Ziehl-Neelson method of staining. The first specimen from a suspected inmate was obtained on the first day of examination after coughing and clearing the back of throat (1st spot).

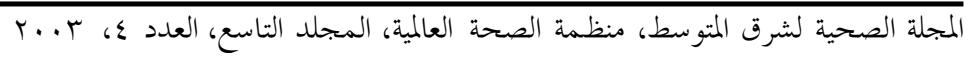


The inmates were given a container to bring the second (overnight) specimen next day. The third and final specimen was collected on the second day (2nd spot).

Individuals with at least 2 positive smear results were diagnosed as sputum smear-positive active pulmonary TB cases, and were registered for the DOTS programme with Sindh TB control programme.

Diagnostic criteria for sputum smearnegative pulmonary TB cases were: at least 3 sputum specimens negative for AFB, no response to a course of broad-spectrum antibiotics and a decision by a clinician to treat with a full course of anti-TB chemotherapy.

Neither X-ray nor culture facilities were available in the jail and were therefore not included in the case definition.

This programme was carried out under the auspices of the government of Sindh with the assistance of the World Health Organization. Efforts were also made to transfer patients to the nearest DOTS programme after their release from prison.

Risk factors for contracting TB infection in prison were studied by random selection of 60 controls among non-suspect individuals and comparing them to the 15 cases.

The Z-test was used to compare the prevalence of TB in prisoners and in the general population. Univariate and multivariate analyses of risk factors for contracting TB in prisons was performed by calculating the odds ratio and 95\% confidence interval. Data management was carried out using Epi-Info, version 6.04 and SPSS, version 10.0 statistical packages.

\section{Results}

We enrolled 386 single male juvenile detainees in the study. Mean age \pm SE was $17.7 \pm$
1.3 years (range 15-23 years) though the official age limit for juvenile jail inmates is 18 years. Pakistanis accounted for 357 $(92.5 \%)$ detainees. The rest were from India or Myanmar (Table 1). Most (87.9) were residents of Karachi. The average family size for the detainees was 8 (range 1-25). They were all imprisoned in 10 barracks, averaging $35.0 \pm 11.7$ prisoners per barrack (range 10-59 prisoners).

In $14.7 \%$ (53) of cases, the father of the inmate was dead. In the rest of the cases $25.4 \%$ (98) of the fathers were labourers, $18.9 \%$ (73) self-employed, $12.7 \%$ (49) in public or private service, $24.4 \%$ (94) had other professions and $4.9 \%$ (19) were unemployed. Of the inmates themselves, $1.0 \%$ (4) were unemployed, $47.7 \%$ (184) were labourers, $17.1 \%$ (66) were selfemployed, $13.2 \%$ (51) were in service, and the remaining $21.0 \%$ (81) had other professions. About 60\% (228) of participants were illiterate, and none had higher secondary school or above education (Table 1 ).

The period of imprisonment was 1-6 months for $52.3 \%$ (202) of jail inmates, 612 months for $20.2 \%$ (78), more than 1 year for $16.3 \%$ (63) and less than 1 month for $11.1 \%$ (43). In addition, $12.7 \%$ (49) of inmates had a previous record of imprisonment. We found that $42.6 \%$ (164) of jail inmates were smokers and 21.5\% (83) were drug users. Among the drug users, 83.6\% were inhaling the drugs and only $1.4 \%$ had a history of injecting (Table 2).

Nine jail inmates had previously been diagnosed with TB; 3 had received the full 6 months treatment, 2 did not receive any treatment, and 4 received irregular treatment, but all of them were symptomatic on clinical examination during our study (Table 3$)$. One of the 3 cases who had received 6 months treatment was also positive for AFB. All had been symptomatic for TB for more than a month. Among the 6 patients who received no or irregular treatment, 3

المجلة الصحية لشرق المتوسط، منظمة الصحة العالمية، المجلد التاسع، العدد ع، بr.ب 
Table 1 Sociodemographic characteristics of juvenile jail detainees $(n=386)$

\begin{tabular}{|c|c|c|}
\hline Characteristic & No. & $\%$ \\
\hline \multicolumn{3}{|l|}{ Age } \\
\hline $15-16$ years & 58 & 15.0 \\
\hline $17-18$ years & 239 & 61.9 \\
\hline $18+$ years & 89 & 23.1 \\
\hline \multicolumn{3}{|l|}{ Education } \\
\hline Uneducated & 228 & 59.1 \\
\hline Primary & 79 & 20.5 \\
\hline Secondary & 79 & 20.5 \\
\hline \multicolumn{3}{|l|}{ Nationality } \\
\hline Pakistania $^{\mathrm{a}}$ & 357 & 92.5 \\
\hline Non-Pakistani & 29 & 7.5 \\
\hline \multicolumn{3}{|l|}{ Residence } \\
\hline Karachi & 320 & 82.9 \\
\hline Outside Karachi & 66 & 17.1 \\
\hline \multicolumn{3}{|l|}{ Father's occupation } \\
\hline Died & 53 & 13.7 \\
\hline Unemployed & 19 & 4.9 \\
\hline Labourer & 98 & 25.4 \\
\hline Government service & 23 & 6.0 \\
\hline Private service & 26 & 6.7 \\
\hline Self employed/business & 73 & 18.9 \\
\hline Driver & 29 & 7.5 \\
\hline Farmer & 26 & 6.7 \\
\hline Fisherman & 31 & 8.0 \\
\hline Other & 8 & 2.2 \\
\hline \multicolumn{3}{|l|}{ Detainee's occupation } \\
\hline Unemployed & 4 & 1.0 \\
\hline Labourer & 184 & 47.7 \\
\hline Service & 51 & 13.2 \\
\hline Self employed/business & 66 & 17.1 \\
\hline Fisherman & 38 & 9.8 \\
\hline Student & 30 & 7.8 \\
\hline Other & 13 & 3.4 \\
\hline \multicolumn{3}{|c|}{ Family members in the household } \\
\hline $1-4$ & 50 & 13.0 \\
\hline $5-8$ & 187 & 48.4 \\
\hline $9-12$ & 123 & 31.9 \\
\hline$>12$ & 26 & 6.7 \\
\hline
\end{tabular}

${ }^{a}$ Area of origin: Karachi (82.9\%); interior Sindh (1.3\%); Punjab (4.1\%); North-West Frontier province (2.6\%); Balochistan (1.3\%); northern areas (0.3\%).

$\mathrm{s}=$ standard deviation complained of cough, fever, weight loss and haemoptysis. One had a history of fever and cough while the other 2 were suffering from chronic cough.

Forty-eight (12.4\%) prisoners had been suffering from 1 or more symptoms (cough, fever, weight loss and haemoptysis) for more than 1 month (Table 4).

Seventy-three jail inmates (18.9\%) were initially suspected for TB on the basis of clinical symptoms, family history and past diagnosis of TB. Of these, 48 had clinical signs and symptoms suggestive of TB, 33 had a family history of TB, while 8 had

Table 2 Risk factors for tuberculosis (TB) among juvenile jail detainees $(n=386)$

\begin{tabular}{lrr}
\hline Characteristic & No. & $\%$ \\
\hline Duration of stay in jail & & \\
$\quad$ < 1 month & 43 & 11.1 \\
1-6 months & 202 & 52.3 \\
$>$ 6-12 months & 78 & 20.2 \\
$\quad$ 1 year & 63 & 16.3 \\
Past history of imprisonment & & \\
Yes & 49 & 12.7 \\
$\quad$ No & 337 & 87.3 \\
Family history of TB & & \\
Yes & 29 & 7.5 \\
$\quad$ No & 347 & 89.9 \\
$\quad$ Don't know & 10 & 2.6 \\
Smoking history & & \\
$\quad$ Smoker & 164 & 42.6 \\
$\quad$ Non-smoker & 222 & 57.5 \\
History of drug use & & \\
$\quad$ Drug user & 83 & 21.5 \\
$\quad$ Non-drug user & 303 & 78.5 \\
Method of drug use & & \\
$\quad$ Inhalation & 61 & 15.8 \\
$\quad$ Ingestion & 9 & 2.3 \\
$\quad$ Inhalation + ingestion & 2 & 0.5 \\
Inhalation + ingestion + injection & 1 & 0.3 \\
$\quad$ Didn't reply & 10 & 2.6 \\
\hline
\end{tabular}




\begin{tabular}{lcc}
\hline $\begin{array}{l}\text { Table } 3 \text { Aspects of previous treatment for } \\
\text { tuberculosis (TB) among juvenile jail } \\
\text { detainees ( } \boldsymbol{n}=\mathbf{3 8 6} \text { ) }\end{array}$ & & \\
\hline Characteristic & No. & $\%$ \\
\hline $\begin{array}{l}\text { History of TB } \\
\quad \text { Yes }\end{array}$ & 9 & 2.3 \\
$\quad$ No & 377 & 97.7 \\
History of treatment for TB & & \\
$\quad$ Yes & 7 & 1.8 \\
$\quad$ No & 2 & 0.5 \\
Course of treatment & & \\
$\quad$ Completed & 3 & 0.8 \\
$\quad$ Not completed & 4 & 1.0 \\
Duration of incomplete & & \\
treatment (months) & & \\
3 & 2 & 0.5 \\
3.5 & 1 & 0.3 \\
5 & 1 & 0.3 \\
Duration of interruption & & \\
to treatment (months) & & \\
$\quad<1$ & 1 & 0.3 \\
$\geq 1$ & 3 & 0.8 \\
& &
\end{tabular}

symptoms suggestive of TB in addition to family history of the disease.

For the AFB smear test, of 73 suspected cases, in 19 (26.0\%) cases we were able to obtain sputum while the rest had saliva and blood in their specimen but no sputum. Of the 19 whose sputum was tested, 5 (26.3\%) showed AFB on microscopy.

On the basis of the AFB smear results, previous diagnosis of the disease and signs and symptoms strongly suggestive of TB, 15 (3.9\%) jail inmates were identified as suffering from TB and selected for the DOTS regimen. Inmates who had tested negative for AFB and had no history of earlier diagnosis were selected for the DOTS regimen mainly on the clinical judgement of the treating physician.

Table 5 shows the risk factors for contracting TB. There was elevated risk among patients who were illiterate, Karachi residents, those whose father was unemployed, smokers or drug users; the results were not, however, statistically significant. However, there was a 7-fold increased risk among those reporting a family history of $\mathrm{TB}$, and this was statistically significant. Table 4 Rates and clinical features of
tuberculosis (TB) infection among juvenile
jail detainees $(n=386)$

\begin{tabular}{|c|c|c|}
\hline Characteristic & No. & $\%$ \\
\hline Registered for DOTS & 15 & 3.9 \\
\hline \multicolumn{3}{|l|}{ Symptoms suggestive of TB } \\
\hline Cough $>4$ weeks & 20 & 5.2 \\
\hline Cough + fever $>4$ weeks & 10 & 2.6 \\
\hline Cough + fever $>4$ weeks & & \\
\hline + weight loss & 1 & 0.3 \\
\hline Cough + fever $>4$ weeks & & \\
\hline $\begin{array}{l}\text { + weight loss + haemoptysis } \\
\text { Cough + fever }>4 \text { weeks }\end{array}$ & 4 & 1.0 \\
\hline + haemoptysis & 1 & 0.3 \\
\hline Cough $>4$ weeks & & \\
\hline + haemoptysis & 2 & 0.5 \\
\hline Fever $>4$ weeks & 4 & 1.0 \\
\hline Weight loss + haemoptysis & 1 & 0.3 \\
\hline Haemoptysis & 5 & 1.3 \\
\hline \multicolumn{3}{|l|}{ Sputum smear microscopy } \\
\hline \multicolumn{3}{|l|}{ Specimen 1} \\
\hline Positive sputum & 1 & 0.3 \\
\hline Negative sputum & 17 & 4.4 \\
\hline Fresh blood & 5 & 1.3 \\
\hline Saliva & 50 & 13.0 \\
\hline \multicolumn{3}{|l|}{ Specimen 2} \\
\hline Positive sputum & 3 & 0.8 \\
\hline Negative sputum & 16 & 4.1 \\
\hline Fresh blood & 4 & 1.0 \\
\hline Saliva & 50 & 13.0 \\
\hline \multicolumn{3}{|l|}{ Specimen 3} \\
\hline Positive sputum & 3 & 0.8 \\
\hline Negative sputum & 16 & 4.1 \\
\hline Fresh blood & 4 & 1.0 \\
\hline Saliva & 50 & 13.0 \\
\hline
\end{tabular}

المجلة الصحية لشرق المتوسط، منظمة الصحة العالمية، المجلد التاسع، العدد ؟، ب...ب 


\begin{tabular}{|c|c|c|c|c|c|c|c|c|}
\hline \multirow[t]{2}{*}{ Risk factor } & \multicolumn{2}{|c|}{$\begin{array}{l}\text { Cases } \\
(n=15)\end{array}$} & \multicolumn{2}{|c|}{$\begin{array}{l}\text { Controls } \\
(n=60)\end{array}$} & \multirow[t]{2}{*}{$\begin{array}{l}\text { Crude } \\
\text { OR }\end{array}$} & \multirow[t]{2}{*}{$95 \% \mathrm{Cl}$} & \multirow[t]{2}{*}{$\begin{array}{l}\text { Adjusted } \\
\text { OR }\end{array}$} & \multirow[t]{2}{*}{ d $95 \% \mathrm{Cl}$} \\
\hline & No. & $\%$ & No. & $\%$ & & & & \\
\hline \multicolumn{9}{|l|}{ Education } \\
\hline Uneducated & 10 & 66.7 & 36 & 60.0 & 1.33 & $0.35-5.24$ & 1.33 & $0.36-5.60$ \\
\hline Educated & 5 & 33.3 & 24 & 40.0 & & & & \\
\hline \multicolumn{9}{|l|}{ Nationality } \\
\hline Pakistani & 15 & 100 & 57 & 95.0 & ND & & ND & \\
\hline Non-Pakistani & 0 & 0 & 3 & 5.0 & & & & \\
\hline \multicolumn{9}{|l|}{ Residence } \\
\hline Karachi & 14 & 93.3 & 52 & 86.7 & 2.15 & $0.23-50.6$ & 2.14 & $0.25-102.3$ \\
\hline Outside Karachi & 1 & 6.7 & 8 & 13.3 & & & & \\
\hline \multicolumn{9}{|l|}{ Father's occupation } \\
\hline Died or unemployed & 3 & 20.0 & 7 & 11.7 & 1.89 & $0.23-10.20$ & 1.87 & $0.27-9.84$ \\
\hline Employed & 12 & 80.0 & 53 & 88.3 & & & & \\
\hline \multicolumn{9}{|c|}{$\begin{array}{l}\text { Number of family members in } \\
\text { household }\end{array}$} \\
\hline$>6$ & 9 & 60.0 & 45 & 75.0 & 0.50 & $0.13-1.94$ & 0.51 & $0.13-2.03$ \\
\hline 6 or less & 6 & 40.0 & 15 & 25.0 & & & & \\
\hline \multicolumn{9}{|l|}{$\begin{array}{l}\text { Duration of stay in jail } \\
\text { (months) }\end{array}$} \\
\hline$>6$ & 5 & 33.3 & 18 & 30.0 & 1.17 & $0.29-4.53$ & 1.16 & $0.27-4.42$ \\
\hline$\leq 6$ & 10 & 66.7 & 42 & 70.0 & & & & \\
\hline \multicolumn{9}{|c|}{ Past history of imprisonment } \\
\hline Yes & 0 & 0 & 11 & 18.3 & ND & & ND & \\
\hline No & 15 & 100 & 49 & 81.7 & & & & \\
\hline \multicolumn{9}{|l|}{ Family history of TB } \\
\hline Yes & 4 & 30.8 & 3 & 5.2 & 8.15 & $1.22-58.59$ & $7.78 \quad 1$ & $1.12-62.48^{a}$ \\
\hline No or don't know & 9 & 69.2 & 55 & 94.8 & & & & \\
\hline \multicolumn{9}{|l|}{ Smoking history } \\
\hline Yes & 9 & 60.0 & 29 & 48.3 & 1.60 & $0.44-5.96$ & 1.59 & $0.44-5.37$ \\
\hline No & 6 & 40.0 & 31 & 51.7 & & & & \\
\hline \multicolumn{9}{|l|}{ History of drug use } \\
\hline Yes & 7 & 46.7 & 20 & 33.3 & 1.75 & $0.48-6.42$ & 1.74 & $0.43-6.40$ \\
\hline No & 8 & 53.3 & 40 & 66.7 & & & & \\
\hline
\end{tabular}

OR = odds ratio.

$\mathrm{Cl}=$ confidence interval

aYates corrected chi-squared $=5.21$; Fisher exact $\mathrm{P}$-value $=0.018$.

$N D=$ not determined

\section{Discussion}

We found a $3.9 \%(15 / 386)$ prevalence of TB among the prisoners in Karachi juvenile jail. This high prevalence of the disease in the inmate population may be related to overcrowding, poor ventilation and malnu-

المجلة الصحية لشرق المتوسط، منظمة الصحة العالمة، المجلد التاسع، العدد ع، ب..ب 
trition in the jail environment. Furthermore, poor health care facilities jeopardize adequate treatment of the infection and could possibly result in the development of resistant strains in prisons.

Our study highlights one of the important aspects of $M$. tuberculosis infection in the community-a high rate of poor compliance and the possible emergence of multidrug resistant strains. Of 9 cases diagnosed with TB, 4 had received partial treatment and only 3 had completed their treatment. But all these cases, irrespective of whether they received treatment or not, were symptomatic. The detection of 5 AFB positive cases during our study suggests a high vulnerability of jail inmates to TB. The presence of AFB in the sputum suggests a high level of infectivity. Coughing, overcrowding and poor ventilation produce conditions which allow the bacteria which cause TB to remain viable for a long time, thus exposing everyone who comes into the barracks, whether a prisoner, member of staff, visitor or an investigator, to infection.

Family history was identified as a major risk factor for TB, with 33 (8.5\%) prisoners reporting history of TB in the family. Of these, 8 (24\%) were initially suspected of having TB on the basis of signs and symptoms. Later, 4 (50\%) were selected for the DOTS programme; 2 of them were AFBpositive and 2 had a history of cough, fever, and haemoptysis for more than 1 month.

Poverty was stated as a major reason for not receiving treatment following diagnosis in 14\% (17) of previously diagnosed, but not treated, prisoners. Similarly, in 14\% (17) ignorance of the consequences of the disease may have been the reason, as those prisoners failed to give any explanation for not receiving treatment. Poor compliance to the anti-TB regimen appeared to be re- sponsible for treatment failure in $42 \%$ (37) of cases, circumstances which may favour the emergence of multidrug resistance.

Our study identified a limitation in using the AFB test as the sole criterion for diagnosing TB infection. It certainly improves the specificity of the diagnosis, but at the cost of poor sensitivity. No AFB-positive prisoner was found asymptomatic, suggesting no false positive diagnosis, using this criterion. Many patients suffering from TB infection were, nevertheless, AFB-negative, suggesting the possibility of some false negative results, perhaps due to undetectable levels of AFB in the smears, or poor quality of specimen collection, staining and microscopy. This may be related to indiscriminate use of antibiotics, including antimycobacterial drugs.

Another limitation noted in the study was the language barrier. There were prisoners from the whole of south-east Asia, speaking different languages and dialects. This may be the reason that compliance of the prisoners with regard to sputum collection was poor, even among the prisoners who were complaining of a productive cough. Difficulty was also noted in taking the clinical history of the patients. It was also noted that 2 weeks training of technicians with regard to AFB staining and microscopy may not be sufficient to carry out these procedures independently.

In our study, owing to the absence of radiological support and culture facilities in the jail environment, the treating physician was left with no option but to use his clinical judgement and start the DOTS regimen for 7 previously diagnosed patients who had symptoms and for 3 clinically suspect cases who tested negative for AFB and had no history of the disease. For the effective and rational use of DOTS in prisons, it may be appropriate to have facilities for radiog-

المجلة الصحية لشرق المتوسط، منظمة الصحة العالمية، المجلد التاسع، العدد ع، ب+..r 
raphy and microbial culture in clinically suspected but AFB smear-negative cases before making any judgement regarding treatment.

The finding of this study that jail inmates are at increased risk for TB infection is in line with earlier studies conducted in prisons in other parts of the world [1-3].

It is suggested that a TB control programme be introduced in the jail environment, ensuring regular screening of prisoners for TB infection and the early and effective management of cases. Special attention should be given to those reporting a positive family history of TB as they have proved to be more likely to be infected. There is also a need to ensure that all prisoners who were receiving DOTS during their prison term continue to do so after their release until the course of treatment is completed. Overcrowding and poor sanitation and ventilation provide $M$. tuberculosis an opportunity to persist for long periods and infect others. There is a need to improve ventilation, sanitation and overall living conditions in the jail environment.

\section{Acknowledgement}

This investigation received technical and financial support from the joint WHO Eastern Mediterranean Region (EMRO), Division of Communicable Diseases (DCD) and the WHO special Programme for Research and Training in Tropical Diseases (TDR): The EMRO/DCD/TDR Small Grants Scheme for Operational Research in Tropical and Communicable Diseases.

\section{References}

1. Aerts A et al. Pulmonary tuberculosis in prisons of the ex-USSR state Georgia: results of a nation-wide prevalence survey among sentenced inmates. International journal of tuberculosis and lung disease, 2000, 4(12):1104-10.

2. Coninx $R$ et al. Tuberculosis in prisons in countries with high prevalence. British medical journal, 2000, 320(7232):4402.

3. Rutta $E$ et al. Tuberculosis in a prison population in Mwanza, Tanzania (1994-
1997). International journal of tuberculosis and lung disease, 2001 5(8):703-6.

4. Annual report of the Director General, Health, Biostatistics Section, 20002001. Islamabad, Ministry of Health, 2002:14-16.

5. Treatment of tuberculosis: guidelines for national programmes, 3rd ed. Geneva, World Health Organization, 2003 (WHO/ CDS/TB 2003.313). 